\title{
SUCCESSFUL REHABLILITATION IN Patients With Chronic Disease
}

\begin{abstract}
The aim of medical intervention in patients suffering from chronic diseases is to maintain a life of quality. Patients who have undergone coronary artery bypass surgery provide a good example of an intervention that will not necessarily result in the prolongation of life but the improved quality of life. Rehabilitation outcome should focus on the improved quality of life and the

\section{EALES*, A STEWART*, "UNIVERSITY OF THE WITWATERSRAND * UNIVERSITY OF CAPE TOWN} T NOAKES**, M GOODMAN* issue of who should be responsible for maintaining improved quality of life. In order to determine if self-responsibility was an aspect of improved quality of life 73 subjects and their spouses were followed up over a period of one year: Self-responsibility was identified as a significant variable $(p=0.003)$ in patients with improved quality of life. Based on the evidence provided by this study it was concluded that unless patients accepted responsibility for their rehabilitation they would not have an improved quality of life.
\end{abstract}

\section{INTRODUCTION}

The accepted definition of rehabilitation is that it is the reduction of disability and handicap with or without changes in the underlying impairment. These changes are not unrelated to the individuals in whom they occur although not much attention has been given to the reaction of patients to them. The effects of the disease process can never be separated between body and mind (WHO, 1980).

Human life is the result of human values (Cohen, 1982). Whatever we strive for in life can only be achieved when living. A human life is lived according to a human plan. The aim of medical intervention is to maintain life and it is widely accepted that it is not life itself that is so important but the quality of life. Most diseases are not dramatically fatal but they affect the patients comfort and happiness and as a result the patient can no longer lead life according to plan (Mosteller, 1983).

In chronic disease where the goal of medical intervention cannot be complete cure, the health care provider should strive to achieve improvement in function by decreasing the symptoms and the severity of the disease progression and in this way improve the quality of patients' lives.

Quality of life may be defined in terms of three major components:

1) Functional capacity

2) Perceptions held by the patient

3) Symptoms and their consequences (Wenger et al, 1984)

In patients with cardiac disease the reduction of disability and handicap is

CORRESPONDENCE: Ms C.J. Eales Physiotherapy Department University of the Witwatersrand 7 York Road, Parktown, 2193 considered a more appropriate determinant of outcome than a reduction in mortality or morbidity. There is also consensus that criteria such as function in daily life, productivity, emotional stability and life satisfaction can be considered indicative of the improved quality of life of patients (Wenger et al, 1984).

In coronary artery disease the impairment is coronary atherosclerosis, the disability is the presence of angina and the handicap is the inability to function normally in the community and this leads to poor quality of life (Oldridge, 1986). A common interpretation of rehabilitation for patients with cardiac disease is that they should be "restored and maintained " at optimal clinical, social , vocational and psychological status. This implies that all this would be done for the patient, possibly by a health professional, and that their role would be passive. The definition of the WHO is slightly different and implies that patients should assume some responsibility for their rehabilitation in the process of regaining an as normal as possible place in the community (WHO, 1984).

Rehabilitation outcomes have to focus on the improved quality of life and issues such as the patient's own personal beliefs, perceptions and motivation i.e. the sense of self-responsibility. This sense of self-responsibility in chronic disease is probably the best predictor of reduction of disability and handicap (Oldridge, 1986).

Rehabilitation, as stated above means restoring, or creating a life of acceptable quality for patients who suffer from chronic diseases. Rehabilitation should not be done for people but with them.

Perhaps we as physiotherapists need to look at our perspectives on rehabilitation and should consider five important conceptual changes that Sartorius suggests; (Sartorius, 1992).
- The improvement of overall quality of life as perceived by the patient as well as the patient's family.

- If the quality of life is going to become a criteria for assessing improved rehabilitation, the opinion of those whose life is being changed must become a decisive factor, rather than an interesting point of observation.

- People are different and so are impaired people and rehabilitation workers should be tolerant of these differences. The outcome of rehabilitation should not be judged by the patient's ability to abide by rigid, predetermined rules of "normal" behaviour. Being able to find a job is still considered confirmation of a patient's worth and activities such as help and support of others, the bringing up of children and creative art, are given much less attention and respect than the ability to function in a traditional job.

- People and impairments change over a period of time. These changes as well as the changes in the world that they live in should be respected. It has to be appreciated that rehabilitation is a long-lasting process and people must be accommodated as they move forward in this process. As people are moving forwards towards change the rules and our opinions will have to keep changing too.

- Rehabilitation is an intervention to improve the quality of life so it becomes important to appreciate that there is not a strict distinction between services dealing with rehabilitation and those that aim to help people in other ways. This connection does not only imply the differences between health and rehabilitation services but also between these services and other community services. This will result in unity of purpose and aim and will give rehabilitation a higher priority.

Improving patients' quality of life will include certain factors that are important 
to all health care workers and certain factors that are specifically important to the patient (Cohen, 1982).

The measurement of outcome of treatment, specifically in terms of the patients' perception of changes in their health, has become a very important factor particularly when costly, invasive treatments are concerned (Caine et al, 1991). The emphasis has moved towards assessing outcome in terms of the patient's perception of changes in health over a period of time. There is growing consensus that patients themselves are the only proper judge of their quality of life (Ferrans CE, 1993). Until recently the prevalent methods of judging outcome have been clinical judgement, return to work and survival rates. It does seem that both approaches have merit and should complement each other.

Responsibility is defined as being morally accountable for actions (Oxford Dictionary, 1991). Self-responsibility means that an individual can be held morally accountable for his or her actions regarding the self. This can be in a physical sense, a psychological (attitudinal) sense or an educational sense.

Most people are not concerned about their health until they loose it. In many cases preventing disease means that the individual must give up certain habits, for example smoking, or do things which require an effort, such as exercising regularly. The freedom of individuals to make their own decisions regarding health puts tremendous pressure on governmental resources for health care. Eventually this becomes a national and not an individual responsibility. More doctors and more expensive hospitals will not improve health. J.H. Knowles (1977) argues that the "right" to health should be replaced by a moral obligation to preserve one's health. The individual then would have the "right" to:

1. Better and more information

2. Accessible services of good quality

3. Minimal financial barriers to these services

Individuals who are willing to take responsibility for themselves and follow reasonable rules for healthy living possibly can extend their productive working life by avoiding disease and disability. If this is the case for healthy individuals then those who have had costly intervention because of disease processes should be responsible for following prescribed life style changes to maintain their health (Ginzberg, 1977).

This sense of self-responsibility in chronic disease could probably be the best predictor of reduction of disability and handicap.
A hypothesis can be made that for successful rehabilitation of patients with chronic disease an improved quality of life and acceptance of responsibility for their rehabilitation are prerequisites.

Extensive research has been conducted to determine the quality of life of patients' who have undergone bypass surgery. In the Coronary Artery Surgery Study (CASS, 1984) the life of the patient was considered improved when :

l. There is improved functional status

2. Amelioration of cardiac related symptoms has occurred

3 . There is return to gainful employment and recreational activity

This model was used in this study to identify improved quality of life in patients one year after bypass surgery. Having identified patients with an improved quality of life the hypothesis that self-responsibility was an aspect of improved quality of life, was tested.

Measuring the acceptance of selfresponsibility is however not a well researched area and very little information exists in the literature to guide this process. The model below for testing self-responsibility was suggested by Eales and Stewart (1994).

Acceptance of self-responsibility was established by:

1. The patient's and the spouse/caregiver's knowledge of the chronic nature of the disease.

2. The patient's knowledge of risk factor modification

3. The spouse/care-giver's judgement of the patient's acceptance of responsibility for risk factor modification

4. Patients' ability to modify and control their stress.

\section{MATERIALS AND METHODS}

\section{Subjects}

Seventy three subjects who had undergone coronary artery bypass surgery were selected from three cardio-thoracic units in Johannesburg. Two of the units were from the private sector and one from the public sector. Informed consent was obtained from all patients for both the interviews and to collect information from their medical records. This study was sanctioned by the committee for research on human subjects of the University of the Witwatersrand. (Clearance no. 36/9/92)

\section{Procedure:}

The 73 subjects were interviewed between days 4 - 6 after surgery, six months later and again one year after surgery. Where possible the subjects' spouses or caregivers were also interviewed at 6 months and one year.

At the first interview basic demographic data, risk factors present and medical history were established. At the subsequent interviews the subject's knowledge of his or her medical condition, operative procedure, risk factor modification and medication was established. The six months' interview provided information on the development of self-responsibility and is not considered in the results and discussion of this paper. The spouse or caregiver's knowledge of risk factor modification and medication was also established.

The subject's knowledge of his or her medical condition, operative procedure, risk factor modification and medication was assigned a score. Similarly, the knowledge of the spouse of risk factor modification and medication, was assigned a score. The total score for patients was calculated out of a possible score of 35 and the spouse out of 20.

Statistical analysis: Having identified two groups (improved quality of life; no improved quality of life) a statistical analysis was done to determine which factors were significantly different in the two groups at days 4-6 post-operatively, six months and twelve months. When two variables are categorical (improved quality of life; no improved quality of life), the Chi-squared test is commonly used to examine the null hypothesis which is that the distributions of the variables are independent of each other. If the calculated Chi-squared value is greater than the tabulated value, the null hypothesis should be rejected at the $5 \%$ level of significance.The Mann - Whitney U test was used to compare the ordinal data obtained from each group to see if they differed significantly.

\section{RESULTS:}

\section{Demographic Information}

Of the 73 patients interviewed on admission 58 remained in the study at 12 months. Fifty spouses were also interviewed at 12 months.

On admission there were 63 males and 10 females, by twelve months there were 48 males and 10 females. The dropouts from the study were thus all males. Of these five had died and the others could not be traced.

Seventy five percent of the sample was married. On admission $70 \%$ of the sample was employed, the average annual income was $>\mathrm{R} 50,000$ and the average educational level was $>$ grade 12 . One year later only $37 \%$ of the sample was employed. 
TABLE 1:

The medical factors indicating the severity of the disease

\begin{tabular}{|l|c|c|c|c|}
\hline & LVEF & $\begin{array}{c}\text { No. vessels } \\
\text { bypassed }\end{array}$ & Previous MI & $\begin{array}{c}\text { Previous } \\
\text { CABG }\end{array}$ \\
\hline mean value & $51 \%$ & 2.8 & $58 \%$ & $7 \%$ \\
\hline
\end{tabular}

LVEF (Leff Ventricular Ejection Fraction); MI (Myocardial Infarct); CABG (Coronary Artery Bypass Grafting).

Improved quality of life was evaluated in the sample at 12 months by assessing improved functional capacity, absence of angina and return to work or recreational activities. Complete data was available on 56 of the 58 subjects remaining in the study.

Seventeen patients, all males, had an improved quality of life and 39 subjects did not.

Having established two groups (Group 1 with an improved quality of life and Group 2 with no improved quality of life) all the independent variables could be compared and those that were significantly different are shown in Table 2 and Table 3.

\section{TABLE 2:}

Significant variables in subjects with an improved quality of life on admission

\begin{tabular}{|l|c|c|c|}
\hline & \multicolumn{4}{|c|}{ Chi-square } \\
\hline $\begin{array}{l}\text { Improved quality of life if: } \\
\text { (Categorical data) }\end{array}$ & df & $x^{2}$-value & p-value \\
\hline Male & 1 & 5.307 & 0.012 \\
\hline Married & 1 & 5.439 & 0.020 \\
\hline Income > R50 000 p/a & 1 & 4.736 & 0.030 \\
\hline Normal sex life & 1 & 5.094 & 0.036 \\
\hline
\end{tabular}

Patients with improved quality of life were married men, earning an income greater then R50,000 per year and who regarded their sex life as normal.

\section{TABLE 3:}

Significant variables in subjects with an improved quality of life at twelve months

\begin{tabular}{|l|c|c|c|}
\hline & \multicolumn{3}{|c|}{ Chi-square } \\
\hline $\begin{array}{l}\text { Improved quality of life if: } \\
\text { (Categorical data) }\end{array}$ & df & $x^{2}$-value & p-value \\
\hline Absence of breathlessness & 1 & 6.898 & 0.009 \\
\hline $\begin{array}{l}\text { Knowledge that smoking } \\
\text { had an effect on CVS }\end{array}$ & 1 & 8.662 & 0.003 \\
\hline $\begin{array}{l}\text { Sexual performance } \\
\text { normal or better than before }\end{array}$ & 1 & 9.873 & 0.002 \\
\hline No symptoms post-operatively & 1 & 5.298 & 0.021 \\
\hline $\begin{array}{l}\text { Not depressed } \\
\text { Spouse knew diet } \\
\text { patients had to follow }\end{array}$ & 1 & 6.842 & 0.009 \\
\hline $\begin{array}{l}\text { Spouses considered } \\
\text { operation a cure }\end{array}$ & 1 & 4.325 & 0.038 \\
\hline $\begin{array}{l}\text { Spouse considered patient's } \\
\text { activity levels > pre-operative } \\
\text { level }\end{array}$ & 2 & 8.850 & 0.012 \\
\hline
\end{tabular}

One year after the operation patients with improved quality of life reported their sexual performance to be normal or better than before the operation, they were not depressed, and they had no medical symptoms. Their spouses considered them more active than before the operation and also regarded them as completely cured by the operation.

Identification of self-responsibility as a factor in improved quality of life

Having established two groups of patients, with and without improved quality of life, acceptance of self-responsibility as a factor in improved quality of life could be determined. The statistical analysis is shown in Table 4.

\section{TABLE 4:}

Determining self-responsibility in patients with improved quality of life

\begin{tabular}{|l|c|c|c|}
\hline & $\begin{array}{c}\text { Self- } \\
\text { responsible }\end{array}$ & $\begin{array}{c}\text { Not self- } \\
\text { responsible }\end{array}$ & Total \\
\hline $\begin{array}{l}\text { Improved quality } \\
\text { of life }\end{array}$ & 17 & 0 & 17 \\
\hline $\begin{array}{l}\text { No improved } \\
\text { quality of life }\end{array}$ & 24 & 15 & 39 \\
\hline Total & 41 & 15 & 56 \\
\hline
\end{tabular}

All 17 patients with improved quality of life were responsible. (Chi-square $=8.931$,

$$
\mathrm{p}=0.003 \text { ). }
$$

The following statement can therefore be made: self-responsibility is a significant factor in patients with an improved quality of life.

All the patients remaining in the sample at one year were judged as responsible or not responsible according to the criteria suggested by Eales and Stewart (1994). These included patients' and spouses' knowledge of the chronic nature of the disease, compliance with risk factor modifications and the ability to control stress. All 58 subjects had sufficient data to allow for this analysis as shown in Table 5 and Table 6.

\section{TABLE 5:}

Significant variables evaluated on admission in patients who were self-responsible

\begin{tabular}{|l|c|c|c|}
\hline & \multicolumn{3}{|c|}{ Chi-square } \\
\hline $\begin{array}{l}\text { Patients had accepted } \\
\text { self-responsibility if: } \\
\text { (Categorical data) }\end{array}$ & $\mathrm{df}$ & $\mathrm{x}^{2}$-value & $\mathrm{p}$-value \\
\hline Married & 1 & 7.739 & 0.005 \\
\hline Education >grade 12 & 1 & 6.371 & 0.012 \\
\hline Diabetes Mellitus & 1 & 4.417 & 0.036 \\
\hline Income > 50 000,00 & 1 & 3.863 & 0.049 \\
\hline
\end{tabular}

Self-responsible subjects were married, had a level of education beyond grade 12 , and an income that was greater than R50,000 per annum. All the diabetic patients, who are patients who have learnt to deal with a chronic disease, were in this sample. 
TABLE 6:

Significant variables evaluated at 12 months in patients who were self-responsible

\begin{tabular}{|l|l|l|l|}
\hline & \multicolumn{3}{|c|}{ Chi-square } \\
\hline $\begin{array}{l}\text { Patients accepted } \\
\text { self-responsibility if: } \\
\text { (Categorical data) }\end{array}$ & $\mathrm{df}$ & $\mathrm{x}^{2}$-value & $\mathrm{p}$-value \\
\hline $\begin{array}{l}\text { Satisfied with outcome } \\
\text { of operation }\end{array}$ & 1 & 4.526 & 0.003 \\
\hline Depressed & 1 & 4.462 & 0.035 \\
\hline $\begin{array}{l}\text { Knew effect of smoking } \\
\text { on the CVS }\end{array}$ & 1 & 5.546 & 0.019 \\
\hline & 1 & & \\
\hline Spouses judged patient to be: & & & \\
\hline Cured by the operation & 1 & 6.105 & 0.013 \\
\hline $\begin{array}{l}\text { More active than } \\
\text { before the operation }\end{array}$ & 1 & 7.860 & 0.005 \\
\hline
\end{tabular}

Spouses of the patients who accepted self-responsibility thought they were cured by the operation. The self-responsible patients were depressed. The patients in the group who had accepted self-responsibility were satisfied with the outcome of the operation.

Knowledge scores for subjects were scored out of 35 and consisted of their knowledge of the medical condition, the surgical procedure, and risk factor modification. The spouses were scored out of 20 and evaluated on their knowledge of the chronic nature of the disease and risk factor modification. The statistical analysis of these scores is shown in Table 7.

TABLE 7:

Knowledge scores of subjects and spouses.

\begin{tabular}{|l|c|c|}
\hline Patients & $\begin{array}{c}\text { Mean Score } \\
\text { (Total = 35) }\end{array}$ & $\begin{array}{c}\text { Mann Whitney test } \\
\text { (p-value) }\end{array}$ \\
\hline Group 1 & 17.8 & 0.0177 \\
\hline Group 2 & 14.5 & \\
\hline $\begin{array}{l}\text { Spouse/ } \\
\text { care-giver of: }\end{array}$ & $\begin{array}{l}\text { Mean Score } \\
\text { (Total = 20) }\end{array}$ & \\
\hline Group 1 & 10.9 & 0.0033 \\
\hline Group 2 & 6.4 & \\
\hline
\end{tabular}

Over a period of six months spouses of patients who had become self-responsible were the only group who had improved their knowledge scores. All other groups had less knowledge at 12 months than at six months.

\section{DISCUSSION:}

Patients with improved quality of life were males, married and with an income exceeding R50,000 p.a. The acceptance of self-responsibility is a significant factor for the improved quality of life in patients suffering from chronic disease.

The outcome of rehabilitation cannot be judged as being successful if patients do not have an improved quality of life as well as accepting self-responsibility for their rehabilitation.

All 17 patients with an improved quality of life had accepted self-responsibility. The opposite however is not true because all patients who were self-responsible did not have an improved quality of life.

Medical factors were not predictive for acceptance of selfresponsibility.

The psychosocial factors were more important. That patients had knowledge, had a certain income, were educated, were supported by their spouses and were satisfied with the outcome of the operation were the most important determinants of acceptance of self-responsibility.

\section{CONCLUSION}

Self-responsibility is an important factor in the successful outcome of coronary artery bypass surgery, which in this study was used as an example of chronic disease. The outcome of rehabilitation can be influenced by assisting patients to become responsible for their rehabilitation. Self-responsibility is dependent on the knowledge of the patient, as well as the spouse, on the chronic nature of the disease as well as risk factor modification. Apart from having the knowledge the patient also has to comply to risk factor modification. Patients should have realistic expectations of the outcome of rehabilitation. Such expectations would assist them to be satisfied with the outcome. Satisfaction with the outcome would lead to acceptance of self-responsibility.

\section{REFERENCES}

Caine N, Harrison SCW, Sharples LD, Wallwork J 1991 Prospective study of quality of life before and after coronary artery bypass grafting British Medical Journal 302: 511-516

CASS Investigators and their Associates 1983 Coronary Artery Surgery Study (CASS): A randomised trial of coronary artery bypass surgery. Survival data. Circulation 68: 939-950

Cohen C 1982 On the quality of life: Some philosphical reflections. Circulation 66 (suppl III): 29-33

Eales CJ, Stewart AV 1994 Factors which may predict successful rehabilitation in patients who have undergone coronary artery bypass surgery: a pilot study. The South African Journal of Physiotherapy 50: 23-25

Ferrans CE 1990 Quality of Life: Conceptual 1ssues. Seminars in Oncology Nursing; 6: 248-254

Ginzberg, E 1977 The sacred cows of health manpower. Man and Medicine, 2: 235-242

Knowles JH 1977 Responsibility for Health. Science Editorial 198: 4322

Mosteller F, Gilbert JP, McPeek B 1980 Reporting standards and research strategies for controlled trials: Agenda for the editor. Controlled Clinical Trials 1: 1

Oldridge NB 1986 Cardiac Rehabilitation, Self-Responsibility, and Quality of Life Journal of Cardiopulmonary Rehabilitation 6: 53-156 Oxford Dictionary 1992 Oxford University Press, New York

Sartorius N 1992 Rehabilitation and Quality of Life. Hospital and Community Psychiatry 43: 1180-1181

Wenger NK, Mattson ME, Furberg CD, Elinson J 1984 Assessment of Quality of Life in Clinical Trials of Cardiovascular Therapies. The American Journal of Cardiology; 54: 908-913

World Health Organization 1980 International classification of impairments, disabilities, and handicaps. Geneva

World Health Organization 1983 Health education in self-care: Possibilities and limitations. Report of a scientific consultation. Geneva: November: 21-25 